\title{
Dynamical systems modelling
}

\author{
Steven J. Lade, ${ }^{1,2}$ John M. Anderies, 3 \\ Paul Currie ${ }^{4,5}$ and Juan C. Rocha ${ }^{1,6}$ \\ ${ }^{1}$ STOCKHOLM RESILIENCE CENTRE, STOCKHOLM UNIVERSITY, STOCKHOLM, SWEDEN \\ ${ }^{2}$ FENNER SCHOOL OF ENVIRONMENT AND SOCIETY, THE AUSTRALIAN NATIONAL UNIVERSITY, CANBERRA, AUSTRALIA \\ ${ }^{3}$ SCHOOL OF SUSTAINABILITY AND SCHOOL OF HUMAN EVOLUTION AND SOCIAL CHANGE, \\ ARIZONA STATE UNIVERSITY, TEMPE, ARIZONA, USA \\ ${ }^{4}$ ICLEI AFRICA, CAPE TOWN, SOUTH AFRICA \\ ${ }^{5}$ CENTRE FOR SUSTAINABILITY TRANSITIONS, STELLENBOSCH UNIVERSITY, STELLENBOSCH, SOUTH AFRICA

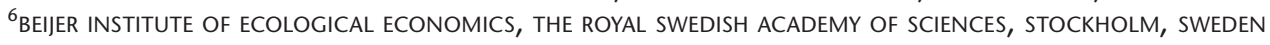

\section{Key methods discussed in this chapter}

Causal loop diagrams, loop analysis, qualitative analysis of differential equations (including bifurcation analysis and stability analysis), numerical simulation of dynamical systems

\section{Connections to other chapters}

Systems scoping (Chapter 5) and participatory modelling and planning (Chapter 13) methods can help to construct the dynamical systems model. Statistical methods (Chapter 18) can be used to parameterise the model and/or test its outputs. The results of dynamical systems models are often used for futures analysis (Chapter 10) or scenario development (Chapter 11). Agent-based modelling (Chapter 28) is a closely related dynamical modelling method.

\section{Introduction}

Dynamical systems modelling provides a rigorous approach for studying how causal interactions within a social-ecological systems (SES) lead to dynamics at the system level. In studies of SES, dynamical systems models are generally used at an aggregated level, e.g. modelling total fish stocks or average harvester effort, rather than modelling the life cycles of individual fish or the effort level dynamics of individual harvesters, as might be done in an agent-based model (Chapter 28). Dynamical systems modelling provides conceptual, mathematical and computational tools to deal with key SES concepts such as feedbacks, non-linearity and regime shifts.

The modern notion of dynamical systems began with the work of Poincare (1890; see Holmes 2007), who studied the qualitative dynamics generated by systems of non-linear differential equations. The advent of modern digital computing permitted advances in the numerical study of dynamical systems, most famously when Edward Lorenz, a meteorologist, discovered sensitivity to initial conditions, later named chaos, when performing computer simulations of air movement in the atmosphere (Lorenz 1963). Concepts such as chaos and 


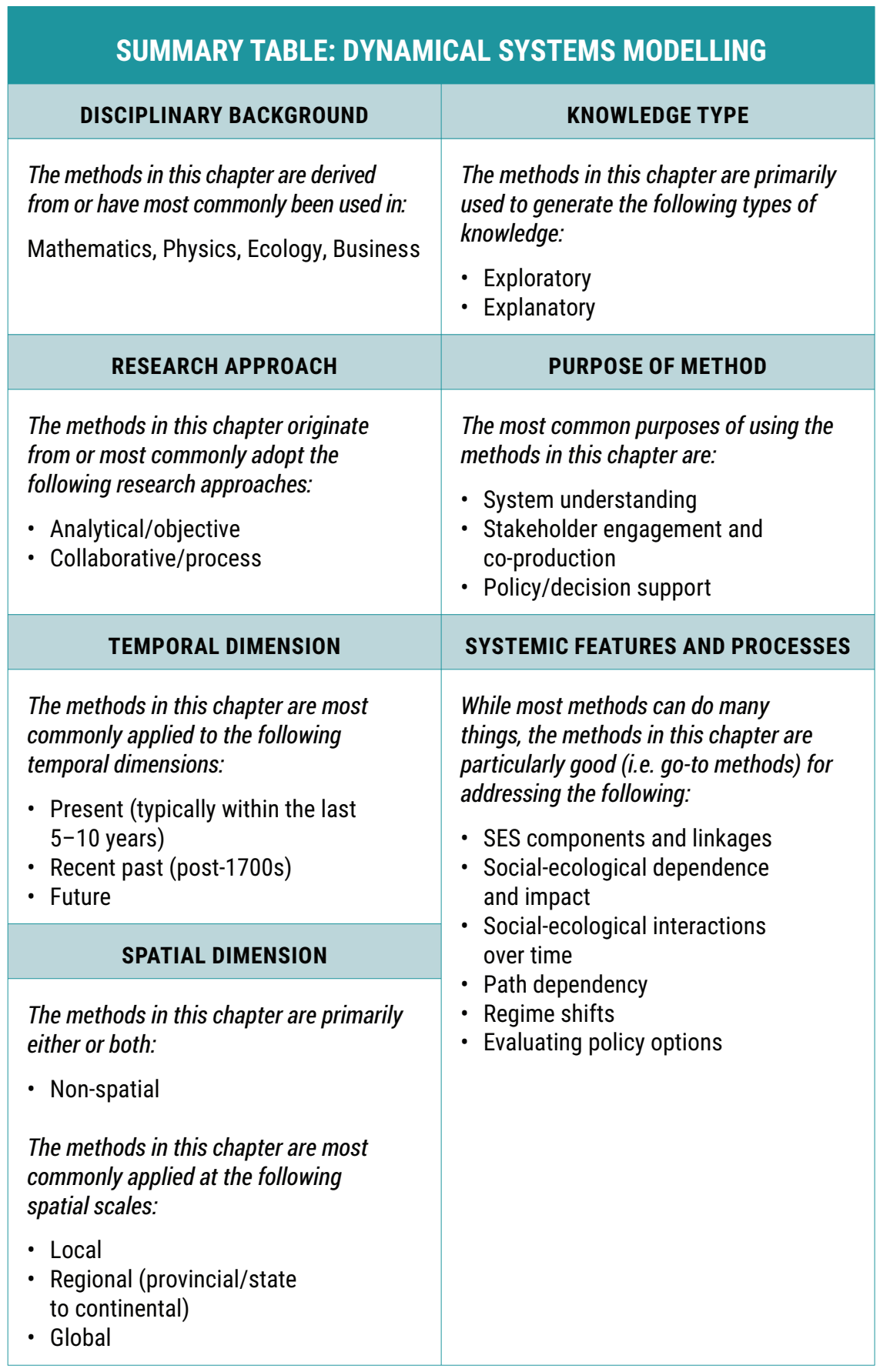


bifurcations were mathematically formalised in the 1980s through work by researchers such as Guckenheimer and Holmes (1983). These and other dynamical systems concepts have influenced the development of many classical concepts used first in theoretical ecology and later in research on the resilience of SES, such as feedbacks, attractors, regime shifts, slow and fast variables, and definitions of resilience itself.

Computer-based tools for numerically solving dynamical systems were taken up by other academic fields for scenario development and planning (see Chapters 10 and 11). These modelling traditions were developed first in the military and later in industrial development, policy design and management sciences. In these fields, dynamical systems modelling is more commonly known as 'system dynamics'. A famous example of system dynamics is the World3 model developed by MIT professor Jay Forrester, which inspired the seminal book Limits to Growth (Meadows et al. 1972). The system dynamics tradition generally emphasises graphical methods for model construction and analysis, which are well suited to participatory settings (see Chapter 13). Causal loop diagrams, for example, provide a frequently used graphical representation of feedbacks.

Today, dynamical systems modelling is a highly interdisciplinary field and a core method for the study of social-ecological and other complex systems. Elements from both the system dynamics and mathematical dynamical systems traditions are widely used in SES research. Dynamical systems models of SES range from empirically parameterised models of a specific case (Elsawah et al. 2017) through to abstract models used to develop theory about SES dynamics (Lade et al. 2013). At the broadest level, dynamical systems modelling promotes a 'systems view' that sees elements of an SES as causally interconnected and interdependent.

\section{SES problems and questions}

Dynamical systems methods are used by individual researchers or collectively among groups of scientists and stakeholders for a wide range of purposes, including:

- Mapping the structure of causal relationships within a system (e.g. what are the social, ecological and social-ecological interactions within Lake Victoria fisheries? (Downing et al. 2014))

- Understanding how system-level dynamics result from causal relationships (e.g. what social and ecological mechanisms led to the collapse of the Baltic cod fishery? (Lade et al. 2015)). What poverty traps are produced by different poverty-environment relationships? (Lade et al. 2017). What mechanisms and drivers determine the state of a managed fire-driven rangeland system? (Anderies, Janssen, and Walker 2002))

- Predicting future dynamics of an SES in response to policy decisions and other drivers (e.g. how will natural perturbations and management decisions affect a coastal fishery? (Martone, Bodini, and Micheli 2017)). How will water supply and demand in the Australian Capital Territory respond to climate changes and management decisions? (Elsawah, McLucas, and Mazanov 2015))

A common use of dynamical systems models is to perform simulations that produce the model's behaviour over time. These simulations can be used to validate a model based on past dynamics and to predict not only a system's future dynamics but also the effects of different interventions or policies on future dynamics. However, there are many other concepts and methods in dynamical systems modelling that are well suited to studying research questions involving key SES concepts, e.g. resilience, feedbacks, attractors and regime shifts. These other methods and concepts, elaborated in Section 'Brief description of key methods', may even have triggered the original development of these SES concepts. 
Dynamical systems approaches are also well suited to facilitating participatory processes (see Chapter 13). First, a complete model or model-under-development is a useful boundary object to show how each stakeholder or action contributes to system behaviour. Bringing stakeholders together to discuss a systemic problem challenges their preconceptions and tests their assumptions against larger system behaviour as elucidated in a model, often leading to changed actor and system behaviours. Second, testing the assumptions of the model builders and stakeholders as the model is built results in more robust causal links and therefore a better system model. Finally, once stakeholders are satisfied that the model displays accurate baseline behaviours, policy and intervention scenario options can be incorporated into the model and their results tested against these behaviours. Policy options could include environmental water provision or pumping restrictions in groundwater social-ecological models; subsidies, water pricing and regulations on the salt content of irrigation water; land management choices in irrigation agriculture models; and water supply and demand management options in public water-distribution models (Elsawah et al. 2017).

\section{Brief description of key methods}

In a dynamical systems model, dynamics result from interactions between different variables within the system. These variables could be properties of actors or groups (e.g. wealth or opinions), properties of species (e.g. population) or other biophysical quantities (e.g. temperature). Causal relationships between these variables could represent anything from biophysical laws to a stakeholder's belief about how the relationship operates. Methods for representing and analysing these relationships range from graphical representations that can be constructed by hand to computational simulations and analyses using formal mathematical methods (Table 26.1).

The first step in a dynamical systems analysis is often the construction of a causal loop diagram, which maps out causal relationships within the SES. The process of constructing the causal loop diagram can help to develop a shared understanding of the SES among multiple stakeholders (see Chapter 13). Especially in participatory settings, a causal loop diagram and its loop analysis may be the endpoint of the dynamical systems methodology.

Causal loop diagrams are well suited to identifying feedback loops in which a chain of causal mechanisms forms a closed loop of cause and effect. Feedback loops are generally classed as either 'reinforcing' or 'balancing'. In a reinforcing feedback loop, the initial changes to a variable are amplified by the feedback loop, generally leading to the system accelerating change. In a balancing feedback loop, the initial changes to a variable are counterbalanced by the feedback loop, generally leading to the system resisting change. 'Reinforcing' and 'balancing' feedback loops are also referred to as 'positive' and 'negative', respectively, where these terms are understood in a mathematical rather than normative sense as amplifying or dampening initial changes. In loop analyses, these feedback loops are identified to help explain system dynamics.

The foundation of any computational or mathematical study of a dynamical systems model is to formulate a set of differential equations (where time is continuous) or difference equations (where time is discrete, i.e. increases in steps). These equations specify how variables in the system change given information about their current states. They can be represented graphically using a stock and flow diagram, or mathematically in equation form.

Stock and flow diagrams represent causal relationships, like in causal loop diagrams, but also distinguish between 'stocks', which are variables that accumulate over time, and 'flows', which increase or decrease stocks over time. The level of water in a bathtub, for example, could be a stock and the flows of water in through the tap and out through the 
Table 26.1 Summary of key methods used in dynamical systems modelling

\begin{tabular}{|c|c|c|}
\hline Method & Description & References \\
\hline $\begin{array}{l}\text { Causal loop } \\
\text { diagram }\end{array}$ & $\begin{array}{l}\text { A causal loop diagram is a technique to } \\
\text { map out the feedback structure of a system, } \\
\text { identifying reinforcing or balancing feedback } \\
\text { behaviours. }\end{array}$ & $\begin{array}{l}\text { Key introductory texts } \\
\text { Sterman 2000; } \\
\text { Maani and Cavana } 2007 \\
\text { Applications to SES } \\
\text { Fazey et al. 2011; } \\
\text { Hanspach et al. 2014; } \\
\text { Pollard, Biggs, and Du Toit 2014; } \\
\text { Kim et al. } 2017\end{array}$ \\
\hline Loop analysis & $\begin{array}{l}\text { Loop analysis infers possible stability } \\
\text { properties of a system based on feedback } \\
\text { loops in the causal loop diagram. It may } \\
\text { involve comparison against reference } \\
\text { archetypes or modes, or assessment of loop } \\
\text { strength. }\end{array}$ & $\begin{array}{l}\text { Key introductory texts } \\
\text { Puccia and Levins 1985; } \\
\text { Justus } 2005 \\
\text { Applications to SES } \\
\text { Downing et al. 2014; } \\
\text { Martone, Bodini, and Micheli 2017; } \\
\text { Abram and Dyke } 2018\end{array}$ \\
\hline $\begin{array}{l}\text { Qualitative } \\
\text { analysis of } \\
\text { differential } \\
\text { equations }\end{array}$ & $\begin{array}{l}\text { Bifurcation and stability analysis are powerful } \\
\text { tools to determine the existence of and } \\
\text { characterise dynamical patterns such as } \\
\text { attractors and transitions between them } \\
\text { (such as regime shifts). }\end{array}$ & $\begin{array}{l}\text { Key introductory texts } \\
\text { Strogatz 1994; } \\
\text { Kuznetsov 2013 } \\
\text { Applications to SES } \\
\text { Anderies, Janssen, and } \\
\text { Walker 2002; } \\
\text { Anderies 2006; } \\
\text { Lade et al. 2015; } \\
\text { Lade et al. 2017; } \\
\text { Tekwa et al. } 2019\end{array}$ \\
\hline $\begin{array}{l}\text { Numerical } \\
\text { simulation } \\
\text { of dynamical } \\
\text { systems }\end{array}$ & $\begin{array}{l}\text { Numerical simulation of dynamical systems } \\
\text { models produces behaviour trends over } \\
\text { time and allows the testing of scenarios. } \\
\text { These models are implemented using } \\
\text { differential or difference equations, but can } \\
\text { also be represented graphically using stock } \\
\text { and flow diagrams. Algorithms such as the } \\
\text { Euler or Runge-Kutta methods numerically } \\
\text { solve differential equations to produce the } \\
\text { dynamics of variables. Researchers often use } \\
\text { software with these algorithms built in. }\end{array}$ & $\begin{array}{l}\text { Key introductory texts } \\
\text { Sterman } 2000 ; \\
\text { Butcher } 2016 \\
\text { Applications to SES } \\
\text { Cifdaloz et al. 2010; } \\
\text { Elsawah et al. } 2017 \text { (see listed cases); } \\
\text { Pizzitutti et al. } 2017\end{array}$ \\
\hline
\end{tabular}

plughole are 'flows'. Other variables, called 'dynamic variables' or 'intermediate variables', mediate causal relationships between different stocks or flows. The water temperature perceived by somebody in the bath, for example, could be an intermediate variable that is causally affected by the actual water temperature and causes a change, depending on the person's behaviour, in the rate of inflow of hot and cold water into the bath.

Underlying a stock and flow diagram is a set of differential or difference equations that some modelling approaches present directly. 
- A paradigmatic ecological differential equation is the logistic equation (Verhulst 1845, 1847) for the growth of a population $P$,

$$
\frac{d P}{d t}=r P\left(1-\frac{P}{K}\right)
$$

Here $d P / d t$ denotes the rate of change of the population $P$. The logistic equation assumes a rate of population growth proportional to the population size for a low population (with proportionality $r$ ), which unbounded would produce exponential growth. At higher population sizes, however, the growth of the population saturates at carrying capacity $K$.

- The replicator equation from evolutionary game theory is an example of a commonly used differential equation describing human behaviour (Cressman and Tao 2014). It states that the fraction of individuals $f_{i}$ that follow strategy $i$ changes over time at a rate

$$
\frac{d f_{i}}{d t}=\left(u_{i}-\bar{u}\right) f_{i},
$$

where $u_{i}$ is the payoff or utility associated with strategy $i$, and $\bar{u}=\sum_{i} u_{i} f_{i}$ is the population average payoff. The replicator equation assumes that individuals randomly encounter other individuals in a well-mixed population and switch strategies at a rate proportional to the difference between their payoffs (Cressman and Tao 2014).

While a theoretical pedigree such as that of the logistic equation or the replicator equation can help to build confidence in the choice of an equation, dynamical systems models are often also built from assumed or elicited knowledge about the causal relationships in an SES, e.g. from the causal loop diagrams described above (see Chapter 13). Statistical methods (see Chapter 18) can compare the fit of different forms of model equations to data, or produce non-parametric fits using interpolation.

After specifying the forms of relationships between variables through a stock and flow diagram or differential or difference equations, the final steps before a numerical simulation can be performed are to assign values to the model's parameters and initial values (also called 'initial conditions') to all stocks. Parameters, such as $r$ and $K$ in the logistic equation above, are quantities that are prescribed externally to the model and usually remain constant for the duration of the simulation. Parameter values can be chosen from previous knowledge about the SES, fitted to historical trends using statistical methods (see Chapter 18), or alternatively set to a range of different values to explore sensitivity of the model's dynamics to parameter values.

Once the model is fully specified, the difference or differential equations can be solved to produce time series of the variables in the systems. Numerical solution methods are readily available in many software products or can be programmed directly by the researcher. Symbolic mathematical solutions can be achieved only in rare cases. These time series can be used to project future states of the system, test the fit of the model to historical data or explore how the model's dynamics depend on changes to parameters within the model.

Beyond numerical simulation, a range of mathematical methods study the qualitative dynamics of dynamical systems. Here 'qualitative' refers to the differences between the various dynamical patterns that dynamical systems can display.

- Stability analysis can identify attractors, which are states that an SES approaches in its long-term dynamics. Attractors can be points (equilibrium points), stable oscillations (limit cycles) or more complicated geometric objects (strange attractors). 
- State space diagrams and stability landscapes can graphically represent attractors and basins of attraction. A basin of attraction is the set of initial conditions whose dynamics approach the attractor. The resilience of SES has often been conceptualised using various aspects of the basin of attraction (Walker et al. 2004; Meyer 2016; Donges and Barfuss 2017). Stability landscapes, which are often sketched qualitatively, have a precise definition within dynamical systems theory (Strogatz 1994).

- Bifurcations are sudden, qualitative changes in system dynamics (where 'sudden' is with respect to changes in some external parameter). Regime shifts in ecological systems (Scheffer et al. 2001) and SES (Lade et al. 2013) are commonly associated with a type of bifurcation called the fold bifurcation in which an attractor disappears, forcing a transition to another attractor. Mathematical tools (such as normal forms) and computational tools (such as bifurcation continuation) can help to characterise bifurcations. There exists a large family of bifurcations (Kuznetsov 2013), although few of them have been studied in SES.

- Bifurcation diagrams can be used to graphically represent regime shifts and accompanying phenomena such as hysteresis (Scheffer et al. 2001). These diagrams plot how the stable and unstable states of a system depend on a chosen parameter. Hysteresis is a form of path dependence where increasing a parameter and then decreasing the parameter to its original value does not return the system to its original state. It commonly appears as an S-curve in bifurcation diagrams where the corners of the $\mathrm{S}$ are a pair of fold bifurcations (Scheffer et al. 2001).

- The importance of considering fast and slow variables is a common theme in resilience research (Biggs, Schlüter, and Schoon 2015). Whereas fast and slow variables are often identified heuristically, singular perturbation theory (Kuehn 2015) can formally decompose a model into fast and slow components. Crépin (2007), for example, decomposed a coral reef ecosystem model into fast variables (algae and herbivore biomass) and a slow variable (coral biomass).

\section{Limitations}

Dynamical systems models can be initially developed without quantitative data, relying on the mental models of model builders or stakeholders in participatory settings (see Chapter 13), or using previous literature and theories for theoretical models. This is useful for modelling in data-scarce environments, as system behaviour can be explored at a high level without data, and model accuracy can be improved as data become available. However, mental models require wide substantiation or validation by experts and their limitations must be acknowledged.

Large stock and flow models or simulation models can make detailed statements about the dynamics of the SES being studied. However, constructing these models is both data and time intensive, requiring validation of each stage as the modelling process continues in order to retain confidence in the system behaviour it is representing. Even with a rigorous validation process, it can be difficult to fully understand and analyse the operation of such a large model. Large and complicated system diagrams can also hinder communication and the development of shared system understanding.

At the other extreme of complexity, simple models can deliver transparent and generalisable insights but can be more challenging to develop than complex models. Simple models require difficult decisions about what simplifying assumptions one can make to maximise clarity, tractability, reproducibility and generalisability without giving up too much representativeness (the extent to which the model matches empirical reality, e.g. its capacity to predict outcomes). Simple models can make general statements about SES but are of limited use when analysing outcomes and presenting options for intervention in specific systems. 
Dynamical systems methods focus on system-level phenomena, such as feedbacks, with less attention paid to the roles, agency and decision-making processes of individual actors in that system. Actor heterogeneity can be included, e.g. through variables representing different groups, or a variable that characterises the variability of a property across a population. Decision-making processes can be represented through causal relationships between the decision context and the consequences of a choice. However, these representations are generally less intuitive than in actor-focused methods such as agent-based modelling (see Chapter 28).

\section{Resource implications}

Causal loop diagrams can be sketched with pen and paper or created with graphical computer software such as Stella (iseesystems.com), Vensim (vensim.com), NetLogo (ccl.northwestern. edu/netlogo), Mental Modeler (mentalmodeler.org) or Insight Maker (insightmaker.com). In participatory modelling (see Chapter 13), an expert facilitator can equip stakeholders with the knowledge to understand and draw their own causal loop diagrams, giving them ownership over the process. This can result in novel outputs.

Most of the software listed above can also be used to construct a computational stock and flow model of dynamical systems. This process would usually require an expert system

\section{Case study 26.1: Using generalised modelling to study the 1980s collapse of the Baltic cod fishery}

Dynamical systems modelling can be used to investigate regime shifts in SES, such as the collapse of the Baltic cod fishery. In the mid- to late 1980s, the Baltic cod fishery suddenly changed from historically high cod biomass and catches to a sprat-dominant ecosystem with low cod abundance (Möllmann et al. 2009). Although the ecological causes and dynamics of this collapse have been well studied, the contribution of social processes to the collapse has received less attention. A dynamical systems modelling study (Lade et al. 2015) filled this research gap by investigating the cod collapse as a social-ecological phenomenon.

A group of ecological and social scientists with expertise on the Baltic cod fishery constructed a conceptual representation of the important variables and processes influencing the collapse of the cod-fishery SES (Figure 26.1). Quantitative and qualitative data on these variables and processes were assembled. Using a dynamical systems method called 'generalised modelling' (Lade and Niiranen 2017), these data were used to estimate the stability of the SES and its subsystems, the directions in which the system variables changed during the collapse, the dominant feedback loops and the possible effects of various policies. Among other results, the model showed that adaptive fisher behaviour temporarily stabilised an otherwise unstable ecological system and allowed the cod boom to persist longer than if the fishers had not adapted. Physical and ecological changes in the Baltic Sea, and increasing pressure from Swedish west coast fishers, eventually outweighed this adaptive capacity and drove the cod fishery into collapse. 
dynamics modeller. The graphical interfaces in these software packages are useful for sharing model design and results with co-authors or stakeholders, but the capacity for sophisticated mathematical analyses by software packages that rely on graphical interfaces can be limited.

To deal directly with the representation and analysis of the dynamical systems as differential or difference equations, a basic level of algebra and calculus is required to understand and manipulate these equations. Some insight can be gained by symbolic manipulation, especially for systems with few variables, which can be performed by hand without computer assistance. However, even small models frequently have behaviour that is too complex for symbolic mathematical solutions. Any general purpose software such as C, Python, MAT$\mathrm{LAB}$ or Julia can be used to numerically solve differential equations; this software often includes inbuilt equation solvers. The inbuilt package AUTO in the specialist free software XPP (Ermentrout 2007) and plugins for MATLAB such as MATCONT (Govaerts, Kuznetsov, and Sautois 2006) and GRIND (SparcS 2018) perform numerical bifurcation continuation to produce bifurcation diagrams.

\section{New directions}

One of the main challenges in constructing quantitative empirical models of SES is the level of knowledge and data about causal relationships that is required to fully specify and

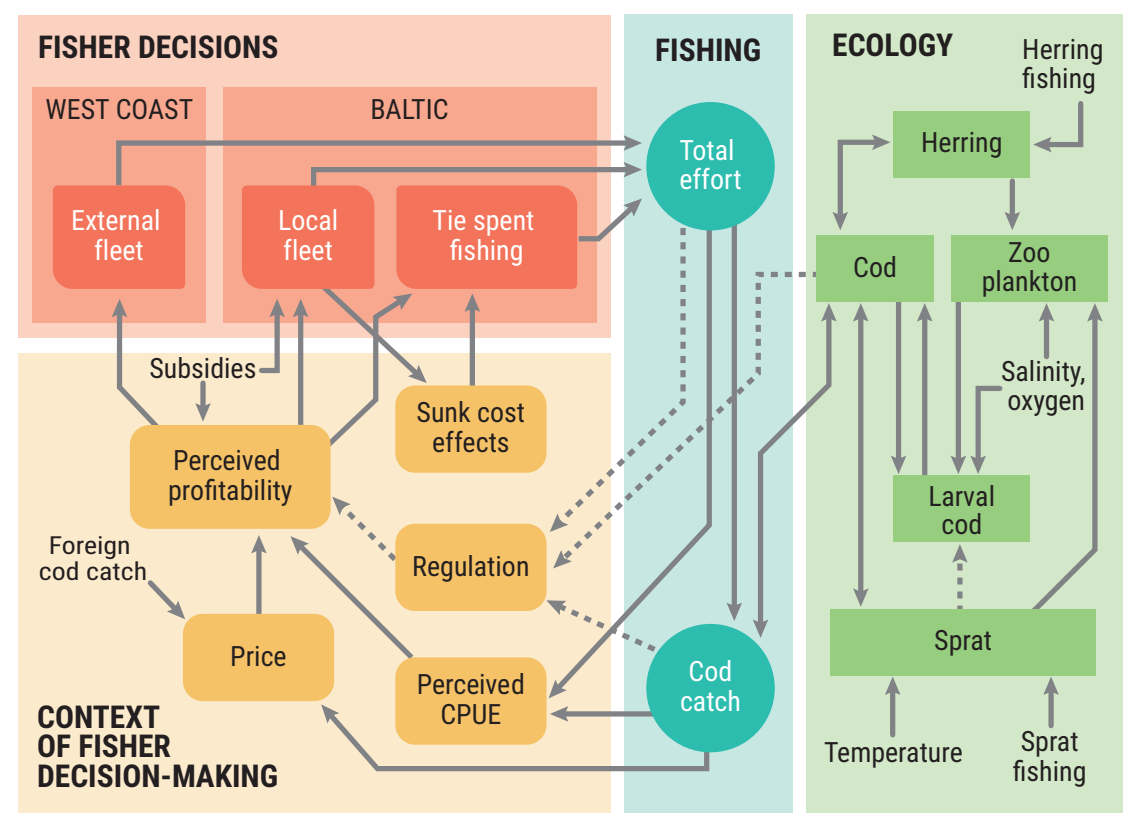

Figure 26.1 Overview of the components and causal relationships included in a social-ecological model of the 1980s Baltic cod fishery (Lade et al. 2015) 
parameterise the model. 'Generalised modelling' is an emerging dynamical systems method for modelling SES that could deal with this challenge (Lade and Niiranen 2017). This modelling approach is useful in situations where the stability of the SES is of primary interest. Estimating stability requires less data than specifying a full simulation model. The generalised modelling procedure specifies exactly which data are required in order to estimate stability and can often incorporate qualitative data. Case study 26.1 summarises how generalised modelling was used to study the 1980s collapse of the Baltic cod fishery.

New developments in computational multi-scale modelling seek to embed outputs of one type of model as inputs to another. This allows system models, which typically operate at one level over one time scale and time step, to interact at multiple levels and times. A regime shift, for example, can be a long process over a wide territory that can be measured and modelled over decades. If the modeller wishes to understand how rapid urban expansion of a number of towns or seasonal resource-demand fluctuations, measured in years or months respectively, contributed to regime shifts, these models could be embedded for greater accuracy and decision support.

Finally, a broad range of dynamical systems theory that is currently unused by dynamical systems modelling in SES research could be used to characterise and explain SES phenomena. There are many more types of bifurcation than the fold bifurcation (Kuznetsov 2013) that is the basis for the regime shift concept. The concept of chaos, in which systems are highly sensitive to initial conditions, is rarely used. There are many dynamical patterns beyond equilibria, such as mixed-mode oscillations (Kuehn 2015), that display fast-slow dynamics reminiscent of the adaptive cycle (Holling and Gunderson 2002). These concepts could aid the analysis of transient dynamics in SES. Numerical methods (Colon, Claessen, and Ghil 2015; Van Strien et al. 2019) or formal statistical mechanics methods could also be used to apply concepts such as bifurcations from dynamical systems theory to agent-based models.

\section{Key readings}

Ford, A. 2010. Modeling the Environment: An Introduction to System Dynamics Models of Environmental Systems (2nd ed). Washington: Island Press.

Roussel, M. 2019. Nonlinear Dynamics: A Hands-on Introductory Survey. San Rafael: Morgan \& Claypool.

Scheffer, M., and Carpenter, S.R. 2003. 'Catastrophic Regime Shifts in Ecosystems: Linking Theory to Observation.' Trends in Ecology and Evolution 18(12): 648-656.

Sterman, J. 2000. 'Business Dynamics: Systems Thinking and Modeling for a Complex World.' Boston: Irwin/McGraw-Hill.

Strogatz, S. 1994. Nonlinear Dynamics and chaos. Philadelphia: Westview.

\section{Acknowledgements}

Steven J. Lade and Juan C. Rocha received support from the Swedish Research Council Formas (grants 2014-589 and 942-2015-731, respectively).

\section{References}

Abram, J.J., and J.G. Dyke 2018. 'Structural Loop Analysis of Complex Ecological Systems.' Ecological Economics 154: 333-342.

Anderies, J.M. 2006. 'Robustness, Institutions, and Large-scale Change in Social-Ecological Systems: The Hohokam of the Phoenix Basin.' Journal of Institutional Economics 2(2): 133-155.

Anderies, J.M., M.A. Janssen, and B.H. Walker. 2002. 'Grazing Management, Resilience, and the Dynamics of a Fire-driven Rangeland System.' Ecosystems 5(1): 23-44. 
Biggs, R., M. Schlüter, and M.L. Schoon, eds. 2015. Principles for Building Resilience: Sustaining Ecosystem Services in Social-Ecological Systems. Cambridge: Cambridge University Press.

Butcher, J.C. 2016. Numerical Methods for Ordinary Differential Equations (3rd ed). Chichester: John Wiley and Sons.

Cifdaloz, O., A. Regmi, J.M. Anderies, and A.A. Rodriguez. 2010. 'Robustness, Vulnerability, and Adaptive Capacity in Small-scale Social-Ecological Systems: The Pumpa Irrigation System in Nepal.' Ecology and Society 15(3): 39.

Colon, C., D. Claessen, and M. Ghil. 2015. 'Bifurcation Analysis of an Agent-based Model for Predator-Prey Interactions.' Ecological Modelling 317: 93-106.

Crépin, A-S. 2007. 'Using Fast and Slow Processes to Manage Resources with Thresholds.' Environmental and Resource Economics 36(2): 191-213.

Cressman, R., and Y. Tao. 2014. 'The Replicator Equation and Other Game Dynamics.' Proceedings of the National Academy of Sciences 111(Supplement 3): 10810-10817.

Donges, J.F., and W. Barfus. 2017. 'From Math to Metaphors and Back Again: Social-Ecological Resilience from a Multi-Agent-Environment Perspective.' GAIA - Ecological Perspectives for Science and Society 26(Supplement 1): 182-190.

Downing, A.S., E. van Nes, J. Balirwa, J. Beuving, P. Bwathondi, L.J. Chapman, I.J.M. Cornelissen et al. 2014. 'Coupled Human and Natural System Dynamics as Key to the Sustainability of Lake Victoria's Ecosystem Services.' Ecology and Society 19(4): 31.

Elsawah, S., A. McLucas, and J. Mazanov. 2015. 'Communicating about Water Issues in Australia: A Simulation/Gaming Approach.' Simulation and Gaming 46(6): 713-741.

Elsawah, S., S.A. Pierce, S.H. Hamilton, H. van Delden, D. Haase, A. Elmahdi, and A.J. Jakeman. 2017. 'An Overview of the System Dynamics Process for Integrated Modelling of Socio-Ecological Systems: Lessons on Good Modelling Practice from Five Case Studies.' Environmental Modelling and Software 93: 127-145.

Ermentrout, B. 2007. XPPAUT. Scholarpedia 2(1): 1399.

Fazey, I., N. Pettorelli, J. Kenter, D. Wagatora, and D. Schuett. 2011. 'Maladaptive Trajectories of Change in Makira, Solomon Islands.' Global Environmental Change 21(4): 1275-1289.

Govaerts, W., Y.A. Kuznetsov, and B. Sautois. 2006. 'MATCONT.' Scholarpedia 1(9): 1375.

Guckenheimer, J., and P. Holmes. 1983. Nonlinear Oscillations, Dynamical Systems and Bifurcations of Vector Fields. New York: Springer.

Hanspach, J., T. Hartel, A.I. Milcu, F. Mikulcak, I. Dorresteijn, J. Loos, H. von Wehrden et al. 2014. 'A Holistic Approach to Studying Social-Ecological Systems and its Application to Southern Transylvania.' Ecology and Society 19(4): 32.

Holling, C.S., and L.H. Gunderson. 2002. 'Resilience and Adaptive Cycles.' In Panarchy: Understanding Transformations in Systems of Humans and Nature, edited by L.H. Gunderson and C.S. Holling, 25-62. Washington: Island Press.

Holmes, P.H. 2007. 'History of Dynamical Systems.' Scholarpedia 2(5): 1843.

Justus, J. 2005. 'Qualitative Scientific Modeling and Loop Analysis.' Philosophy of Science 72: 1272-1286.

Kim, M., S. You, J. Chon, and J. Lee. 2017. 'Sustainable Land-use Planning to Improve the Coastal Resilience of the Social-Ecological Landscape.' Sustainability 9: 1086.

Kuehn, C. 2015. Multiple Time Scale Dynamics. Cham: Springer.

Kuznetsov, Y.A. 2013. Elements of Applied Bifurcation Theory. New York: Springer.

Lade, S.J., L.J. Haider, G. Engström, and M. Schlüter. 2017. 'Resilience Offers Escape from Trapped Thinking on Poverty Alleviation.' Science Advances 3(5): e1603043.

Lade, S.J., and S. Niiranen. 2017. 'Generalized Modeling of Empirical Social-Ecological Systems.' Natural Resource Modeling 30(3): e12129.

Lade, S.J., S. Niiranen, J. Hentati-Sundberg, T. Blenckner, W. Boonstra, K. Orach, M. Quaas, H. Österblom, and M. Schlüter. 2015. 'An Empirical Model of the Baltic Sea Reveals the Importance of Social Dynamics for Ecological Regime Shifts.' Proceedings of the National Academy of Sciences 112(35): $11120-11125$.

Lade, S.J., A. Tavoni, S.A. Levin, and M. Schlüter. 2013. 'Regime Shifts in a Social-Ecological System.' Journal of Theoretical Ecology 6: 359-372.

Lorenz, E. 1963. 'Deterministic Nonperiodic Flow.' Journal of the Atmospheric Sciences 20(2): 130-141.

Maani, K.E., and R.Y. Cavana. 2007. Systems Thinking, System Dynamics. Auckland: Pearson.

Martone, R.G., A. Bodini, and F. Micheli. 2017. 'Identifying Potential Consequences of Natural Perturbations and Management Decisions on a Coastal Fishery Social-Ecological System using Qualitative Loop Analysis.' Ecology and Society 22(1): 34. 
Meadows, D.H., D.L. Meadows, J. Randers, and W.W. Behrens III. 1972. The Limits to Growth. Washington: Potomac Associates.

Meyer, K. 2016. 'A Mathematical Review of Resilience in Ecology.' Natural Resource Modeling 29(3): 339-352.

Möllmann, C., R. Diekmann, B. Müller-Karulis, G. Kornilovs, M. Plikshs, and P. Axe. 2009. 'Reorganization of a Large Marine Ecosystem due to Atmospheric and Anthropogenic Pressure: A Discontinuous Regime Shift in the Central Baltic Sea.' Global Change Biology 15(6): 1377-1393.

Pizzitutti, F., S.J. Walsh, R.R. Rindfuss, R. Gunter, D. Quiroga, R. Tippett, and C.F. Mena. 2017. 'Scenario Planning for Tourism Management: A Participatory and System Dynamics Model Applied to the Galapagos Islands of Ecuador.' Journal of Sustainable Tourism 25(8): 1117-1137.

Poincaré, H.J. 1890. 'Sur le Problème des Trois Corps et les Équations de la Dynamique.' Acta Mathematica 13: 1-270.

Pollard, S., H. Biggs, and D.R. du Toit. 2014. 'A Systemic Framework for Context-based Decision Making in Natural Resource Management: Reflections on an Integrative Assessment of Water and Livelihood Security Outcomes following Policy Reform in South Africa.' Ecology and Society 19(2): 63.

Puccia, C.J., and R. Levins. 1985. Qualitative Modeling of Complex Systems: An Introduction to Loop Analysis and Time Averaging. Cambridge: Harvard University Press.

Scheffer, M., S. Carpenter, J.A. Foley, C. Folke, and B. Walker 2001. 'Catastrophic Shifts in Ecosystems.' Nature 413: 591-596.

SparcS (Synergy program for analyzing resilience and critical transitionS). 2018. GRIND for MAT$L A B$. www.sparcs-center.org/grind.

Sterman, J. 2000. Business Dynamics: Systems Thinking and Modeling for a Complex World. Boston: Irwin/ McGraw-Hill.

Strogatz, S. 1994. Nonlinear Dynamics and Chaos. Philadelphia: Westview.

Tekwa, E.W., E.P. Fenichel, S.A. Levin, and M.L. Pinsky. 2019. 'Path-dependent Institutions Drive Alternative Stable States in Conservation.' Proceedings of the National Academy of Sciences 116(2): 689-694.

Van Strien, M.J., S.H. Huber, J.M. Anderies, and A. Grêt-Regamey. 2019. 'Resilience in SocialEcological Systems: Identifying Stable and Unstable Equilibria with Agent-based Models.' Ecology and Society 24(2): 8.

Verhulst, P-F. 1845. 'Recherches Mathématiques sur la Loi D’Accroissement de la Population.' Nouv. mém. de l'Academie Royale des Sci. et Belles-Lettres de Bruxelles 18: 1-41.

Verhulst, P-F. 1847. 'Deuxième Mémoire sur la Loi D'Accroissement de la Population.' Mém. de l'Academie Royale des Sci., des Lettres et des Beaux-Arts de Belgique 20: 1-32.

Walker, B., C.S. Holling, S.R. Carpenter, and A. Kinzig. 2004. 'Resilience, Adaptability and Transformability in Social-Ecological Systems.' Ecology and Society 9(2): 5. 